\title{
Manipulating Sales Revenue To Achieve Cognitive Reference Points: An Examination Of Large U.S. Public Companies
}

Charles E. Jordan, University of Southern Mississippi, USA Stanley J. Clark, University of Southern Mississippi, USA

Charlotte Hames, University of Southern Mississippi, USA

\begin{abstract}
Significant research (e.g., Carslaw, 1988; Thomas, 1989) provides evidence that managers manipulate earnings to reach cognitive reference points in income. More specifically, when the second-from-the-left earnings digit falls just below zero, management finds ways to round earnings up to just above this breakpoint so that the first earnings digit increases by one. The current study demonstrates that for a sample of large publicly-traded U.S. companies this same type of manipulative behavior appears to be occurring with respect to reported sales revenue.
\end{abstract}

Keywords: income statement manipulation, earnings management, cognitive reference points, and Benford's law

\section{INTRODUCTION}

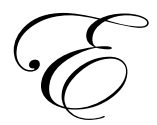

arnings management represents the deliberate manipulation of earnings for personal gain. It can occur because net income results from accrual basis accounting and the many estimates and choices that are required in its application. A specific subset of earnings management examined in the last couple of decades involves earnings manipulation to achieve cognitive reference points in income. The belief here is that managers round up earnings when unrounded earnings fall just short of key cognitive reference points. In particular, managers will round the second-from-the-left earnings digit up to zero if it falls just slightly below this point. The purpose of such rounding is to cause the first earnings digit to increase by one. For example, unrounded earnings of $\$ 2,965$ million would be rounded up to something slightly over $\$ 3,000$ million. This type of earnings management is often referred to as cosmetic earnings management (CEM), and significant research indicates that it occurs in practice (e.g., see Carslaw, 1988; Thomas, 1989).

Another stream of research, unrelated to earnings management, demonstrates the importance of disaggregating accrual earnings into its various components for purposes of predicting future cash flows (e.g., see Barth et al., 2001; Al-Attar and Hussain, 2004). For example, sales revenue represents an important component of accrual earnings, and studies show that sales volatility embodies a crucial determinant of earnings quality (e.g., see Dechow and Dichev, 2002; Francis et al., 2004). Furthermore, Zheng and Strangeland (2007) document that growth rates of sales provide a significant measure of firm quality.

The current study expands the research on both sales and CEM. In particular, recognizing the importance that investors place on sales revenue as a measure of firm quality, do managers round up reported sales revenue to achieve cognitive reference points in a manner similar to the rounding of earnings? Examining a sample of large publicly-traded U.S. companies reveals that, indeed, the second sales digit appears to be rounded up so that the first digit increases by one. 


\section{LITERATURE REVIEW}

Brenner and Brenner (1982) note that humans have a limited amount of memory and that they tend to use this limited memory to store the most relevant information about a price. Carslaw (1988) states that people generally round numbers down rather than up because the process of rounding down is simply easier than rounding up. As Skousen et al. (2004, p. 214) note, "in the eyes of the consumer, a price of $\$ 698$ is more likely to be six hundred something rather than almost seven hundred." Brenner and Brenner (1982) point out that a primary example of this concept in practice is the pricing of gasoline. The price at the pump might be $\$ 3.79^{9 / 10}$ per gallon. Yet, in their minds, consumers almost always round this price down to $\$ 3.79$ rather than rounding it up to the more logical $\$ 3.80$.

Skousen et al. (2004) indicate a similar phenomenon would occur with investors evaluating a firm's earnings. As an example, they note that earnings of $\$ 698,000$ may be perceived by investors as much lower than $\$ 700,000$. Since current earnings act as a signal of future earnings and cash flows, low current earnings will result in a decreased share price while high earnings will result in an increased security price. Thus, when earnings are just below a breakpoint (i.e., a point where the first earnings digit will increase by one), management has incentive to manipulate earnings to just above that breakpoint (AKA a cognitive reference point in income).

Numerous studies demonstrate that this type of earnings management occurs in practice. In the first of these studies, Carslaw (1988) sets the research methodology by examining the second-from-the-left earnings digit for a large number of publicly-traded New Zealand companies. For his sample of firms, he finds a significantly higher incidence of zeros and lower frequency of nines than expected in the second digit in reported earnings. From this evidence, he concludes that managers find ways to manipulate earnings upward to just above the breakpoint when unrounded earnings fall only slightly below the cognitive reference point.

Thomas (1989) replicates Carslaw's (1988) research but does so with publicly-traded U.S. companies and examines firms with positive earnings as well as those with negative income. Carslaw (1988) examines only positive earnings firms. Thomas (1989) finds that rounding earnings to achieve cognitive reference points in income is not isolated to New Zealand companies as his sample of U.S. companies demonstrates a similar trait (i.e., fewer nines and more zeros than expected in the second earnings digit for firms with positive income). Just the opposite result occurs for negative earnings firms (i.e., more nines and fewer zeros than anticipated in the second earnings position).

Niskanen and Keloharju (2000) replicate the Carslaw (1988) and Thomas (1989) studies using Finnish firms. They examine only positive earnings firms and conclude that earnings management to achieve cognitive reference points in income is even more prevalent among Finnish firms than among companies in the U.S. and New Zealand. More specifically, Niskanen and Keloharju (2000) discover that Finnish firms do not limit their rounding up of the second earnings digit merely from nines to zeros but instead round the second digit all the way from sixes and sevens to zeros and ones. With these results, they conclude that the earnings management practiced by Finnish firms is much more than cosmetic.

Examining U.K. firms with positive earnings, Van Caneghem (2002) replicates the earlier studies and draws similar conclusions. When U.K. companies have a nine in the second earnings digit, managers manipulate earnings to round the second digit up to zero, thereby increasing the first digit by one. He makes this conclusion because firms possess more zeros and fewer nines than expected in the second earnings position. Van Caneghem's (2002) primary contribution to the literature on this topic is his demonstration that to achieve the earnings rounding management manipulates short-run, discretionary accruals.

Again using an approach similar to the previous studies, Kinnunen and Koskela (2003) examine a broad sample that includes observations from 22,000 companies reporting in 18 different countries. The results are the same as with all prior studies. Positive earnings firms report a lower frequency of nines and higher rate of zeros than expected in the second earnings digit. The findings are just the opposite for firms with negative earnings. Perhaps their most interesting results are that the likelihood of this earnings management behavior decreases with the amount spent on auditing but increases with the flexibility of GAAP within a country. 
Skousen et al. (2004) replicate the earlier studies on CEM but do so with Japanese firms. Similar to the previous studies, they find that Japanese firms with positive earnings report fewer nines and more zeros than expected in the second earnings digit and just the opposite result occurs with negative earnings firms. Their primary contribution to the literature in this area is that for Japanese firms, the manipulation of earnings is not limited to rounding the second digit to increase the first digit by one. More specifically, they find evidence of rounding the third and fourth digits as well (i.e., the third digit is rounded up to increase the second digit by one while the fourth digit is rounded up to increase the third digit by one).

Guan et al. (2006) replicate the prior studies by examining quarterly reports on U.S. publicly-traded companies. All previous studies had examined annual financials only. Not surprisingly, Guan et al. (2006) discover that firms engage in CEM in all four quarters. Their most intriguing result is that this form of earnings management appears significantly less severe in the fourth quarter relative to the first three quarters. Since only the fourth quarter financials are audited, the authors conclude that auditors play a significant role in reducing this type of manipulative behavior by management.

Jordan et al. (2008) examine CEM to determine if the likelihood of engaging in this behavior is related to specific company characteristics. Analyzing a sample of publicly-traded U.S. companies, their results are similar to all previous studies in that, overall, firms with positive income round earnings up to achieve a one-number-higher first earnings digit when the unrounded second earnings digit falls only slightly below the breakpoint. The main contributions of the Jordan et al. (2008) study are their findings that the probability of management engaging in this type of behavior is related to company size, profitability, and debt leverage. Smaller companies appear more likely to engage in this behavior than larger companies, while less profitable firms practice this type of earnings management more aggressively than more profitable ones. Finally, companies with less debt leverage seem more prone to this manipulative behavior than firms more heavily burdened with debt.

As noted in the preceding paragraphs, numerous studies examine CEM. Following the earliest research by Carslaw (1988), each successive study adds its own nuance to this line of research. However, one dramatic conclusion rings true in each of these varied studies; companies in all samples, regardless of country or time period examined, round earnings to achieve cognitive reference points in income. That is, if the second earnings digit falls slightly below zero, earnings are managed upward to just above this breakpoint so that the first earnings digit increases by one. The purpose of the current research is not to examine CEM with respect to income because prior research clearly demonstrates its existence. The present study seeks to determine whether this type of manipulative behavior occurs with respect to a primary component of earnings (i.e., sales revenue).

Numerous studies show that separating aggregate accrual earnings into its various components improves its ability to predict future cash flows (e.g., see Barth et al., 2001; Hollister et al., 2002; Al-Attar and Hussan, 2004). Sales revenue represents one of the most significant individual components of accrual earnings, and several studies demonstrate its importance in relation to evaluating earnings quality and management performance as well as its ability to predict future cash flows. For example, Dechow and Dichev (2002) show that growth rates in sales provide a strong measure of firm value. Dharan (1987) notes that cash forecasts based on accrual sales are superior to cash flow predictions using cash collection information.

Ertimur et al. (2003) examine revenue and expense surprises surrounding preliminary earnings announcements and conclude that investors value a dollar of revenue surprise more highly than a dollar of expense surprise. Michelson et al. (1995) note that real income smoothing results from changes in sales. Kaplan (1994) shows that executive compensation and turnover are correlated with earnings, share returns, and sales performance measures. Olsen and Dietrich (1985) show that monthly sales announcements of major discount and department stores not only affect earnings, cash flow projections, and security prices of these firms but of their suppliers as well. Finally, Jordan et al. (2007) evaluate the comparative ability of sales, earnings, and cash flow from operations in terms of share price prediction and demonstrate that changes in sales revenue provide superior predictions to changes in either earnings or operating cash flows.

The above studies on sales revenue are explored only briefly in this project because it is their outcomes that are more important than their methodologies. In particular, the sales studies just discussed clearly document the 
significance of this earnings component along several fronts (i.e., in evaluating firm quality, earnings quality, and management performance and in predicting cash flows and share price). Without question, managers understand the benefits, both to themselves and to their firms, of reporting strong sales figures. As noted previously, the literature on CEM consistently demonstrates that managers find ways to manipulate earnings to round up the second earnings digit when it is close to zero so that the first earnings digit increases by one. The current study seeks to ascertain whether this same phenomenon occurs with respect to sales revenue. That is, do managers manipulate sales revenue to round up the second sales revenue digit to zero when the unrounded second digit falls only slightly below zero?

\section{METHODOLOGY}

A key issue in performing digital analysis of a group of numbers is identifying the appropriate expected frequency for each digital position within a number. For example, the number 1,437 has four digits; the number one is the first digit, four is the second digit and so forth. Intuition suggests that each of the numbers one through nine possesses a one-ninth chance of occurring in the first digital position and the numbers zero through nine each have a one-tenth likelihood of appearing in every position to the right of the first digit. However, intuition is wrong when it comes to digital distributions found in naturally occurring numbers.

Simon Newcomb, a nineteenth-century mathematician and astronomer, first developed the notion that digital distributions in naturally occurring numbers do not follow a proportional pattern. When looking up numbers in logarithmic tables, he noted that the first pages were more worn than the latter pages and concluded that the digit one is used more frequently than two and two more often than three and so on. Newcomb developed mathematical theorems for determining the likelihood of a particular digit appearing in each position within a number and published the results of his work in 1881 in the American Journal of Mathematics.

Unfortunately for Newcomb, his work went largely unnoticed. Then, in the late 1920's and early 1930's, a General Electric physicist named Frank Benford made the same discovery and in the same manner as Newcomb. Unaware of Newcomb's work, Benford also noted that the pages containing logarithmic tables for lower numbers were more worn than the pages containing tables for higher numbers and surmised that lower digits appear more frequently in practice than higher digits. Benford developed the same mathematical theorems as Newcomb for specifying the digital frequencies of naturally occurring numbers and published his work in 1938 in the Proceedings of the American Philosophical Society. However, Benford did a better job of selling his research than Newcomb and went to great lengths to demonstrate that his mathematical theorems reflected real life phenomena.

For example, he examined 20,229 observations comprised of such diverse groups of numbers as the drainage areas of rivers, death rates, population statistics, numbers appearing in an issue of Reader's Digest, etc. He did not develop his mathematical theorems until after he evaluated the digital distributions actually occurring in practice. He hypothesized that naturally occurring data (i.e., not invented by man or machine) should form a geometric sequence, and using integral calculus he formulated theorems for the expected digital frequencies of the first and second digits within a number. Benford's theorems described very well the actual digital distributions observed in the many data sets he collected and analyzed. These digital frequencies, now commonly referred to as Benford's Law, appear in Table 1.

For digital positions to the right of the second digit, the expected frequencies converge on a proportional rate (i.e., they approximate $10 \%$ ). Benford's expected digital frequencies do not apply to small numbers (i.e., generally, the numbers must possess at least four digits) nor do they work with numbers subject to known parameters (e.g., invoice numbers, telephone numbers, zip codes, etc.). However, Benford's expected digital frequencies accurately portray the observed frequencies for naturally occurring numbers, and Nigrini (1996) and others (e.g., see Johnson, 2005; Lehman et al., 2007) note that unmanipulated financial statement data conform well to Benford's expected digital frequencies. As such, comparing the digital frequencies actually occurring for a group of financial numbers to their expected (i.e., Benford's) frequencies has often been used to detect fraud or financial statement manipulation. Indeed, every study examining CEM, from Carslaw (1988) to Jordan et al. (2008), uses Benford's expected digital frequencies to evaluate whether managers round up the second earnings digit to achieve cognitive reference points in the first earnings digit. 
Table 1

Benford's Expected Digital Frequencies

\begin{tabular}{cll}
\hline & \multicolumn{2}{l}{$\begin{array}{l}\text { Probability that the digit will } \\
\text { appear in the following position: }\end{array}$} \\
\hline Digit & First & Second \\
\hline 0 & $30.103 \%$ & $11.968 \%$ \\
1 & 17.609 & 11.389 \\
2 & 12.494 & 10.882 \\
3 & 9.691 & 10.433 \\
4 & 7.918 & 10.031 \\
5 & 6.695 & 9.668 \\
6 & 5.799 & 9.337 \\
7 & 5.115 & 9.035 \\
8 & 4.576 & 8.757 \\
9 & & 8.500 \\
\hline
\end{tabular}

Source: Nigrini (1997)

The key digit under investigation is the second digit. For positive earnings firms, if management rounds up the second earnings digit when it falls only slightly below zero, there should exist a lower frequency of high numbers (e.g., eights and nines) and a higher rate of low numbers (e.g., zeros and ones) than expected in the second earnings digit. The opposite result would be expected for firms with negative earnings. The current study uses this same methodology for ascertaining whether firms round sales revenue to achieve cognitive reference points i.e., do they practice cosmetic sales management (CSM)?

To evaluate whether firms engage in CSM, select 2006 financial statement data are examined for the largest 1,002 U.S. publicly-traded companies. The data are collected from the Lexis Nexis Business database. Entity size is measured by total revenue. The target sample size is 1,000 companies, but a couple of extra firms are collected in the event outliers need to be eliminated. Ultimately, though, no outliers are omitted, which results in a sample of 1,002 firms. Admittedly, the largest 1,002 companies do not comprise a random sample of all publicly-traded firms. The largest publicly-traded companies are examined because of their significance or impact. More specifically, a grossly disproportionate percentage of total investment dollars is tied up in these firms relative to the market effect of a randomly generated sample of companies of all sizes. Delineating the sample by entity size represents a limitation of the current study in that its results are generalizable only to the population of large firms; however, that population embodies the most significant companies in existence.

Before examining the digital distributions for the second digit in the sales revenue numbers, the distributions for the second digit in the total assets numbers are examined as a control procedure. More specifically, there exists no a priori reason to believe that management would round up the second digit in total assets to achieve a one-number-higher first digit. If the observed frequencies of digits in the second digital position for total assets conform to Benford's expected proportions, then clear evidence exists that Benford's expected frequencies represent an accurate portrayal of the digital frequencies for unmanipulated financial statement data for the sample firms.

\section{RESULTS}

Table 2 provides the number of times each of the digits zero through nine appears in the second digital position of the total assets number for the 1,002 sample firms. For example, zero occurs as the second digit for 116 firms, one appears as the second digit 109 times and so forth. Table 2 also presents the actual or observed frequencies of each of the digits zero through nine appearing in the second position in the total assets numbers; Benford's expected frequencies are shown as well. Finally, Table 2 provides the $Z$ value and P-level for a proportions test comparing the observed frequency of each digit to its expected (i.e., Benford's) rate of occurrence. 
Table 2

Digital Frequencies in the Second Position of Total Assets

\begin{tabular}{|c|c|c|c|c|c|c|c|c|c|c|}
\hline & & & & & & Digit & & & & \\
\hline & $\mathbf{0}$ & 1 & 2 & 3 & 4 & 5 & 6 & 7 & 8 & 9 \\
\hline $\begin{array}{l}\text { No. of times digit occurs } \\
\text { in second position }\end{array}$ & 116 & 109 & 109 & 109 & 109 & 110 & 81 & 99 & 83 & 77 \\
\hline Observed frequency $(\%)$ & 11.577 & 10.878 & 10.878 & 10.878 & 10.878 & 10.978 & 8.084 & 9.880 & 8.283 & 7.685 \\
\hline Expected frequency $(\%)$ & 11.968 & 11.389 & 10.882 & 10.433 & 10.031 & 9.668 & 9.337 & 9.035 & 8.757 & 8.500 \\
\hline $\mathrm{Z}$ value & -.381 & -.519 & -.004 & .461 & .893 & 1.403 & -1.363 & .933 & -.530 & -.925 \\
\hline P-level & .703 & .611 & .997 & .645 & .372 & .161 & .173 & .351 & .596 & .355 \\
\hline
\end{tabular}

The results in Table 2 provide an important finding in their demonstration that the observed digits in the second position for total assets conform nicely to Benford's expected frequencies. Using a .10 alpha level, Table 2 reveals that the observed frequency of every digit, zero through nine, differs by a statistically insignificant amount from its expected frequency. This finding is important because it suggests that unmanipulated financial statement data for these sample firms follow Benford's expected frequencies, at least with respect to the second digital position.

Table 3 presents the observed and expected frequencies for each of the digits zero through nine appearing in the second digital position of the sales revenue numbers for the 1,002 firms. The results demonstrate what appears to be manipulation to achieve cognitive reference points in sales revenue. In particular, using a .10 alpha level, Table 3 shows that firms report zeros in the second sales digit far more often than expected (i.e., a P-level of .079) and report sevens in the second sales position much less often than expected (i.e., a P-level of .041). All other digits appearing in the second sales revenue position conform to Benford's expected frequencies. This represents a clear pattern of manipulation or rounding to achieve a one-number-higher first digit in sales revenue.

Table 3

Digital Frequencies in the Second Position of Sales Revenue

\begin{tabular}{llllllllllll}
\hline & \multicolumn{1}{c}{ Digit } \\
\hline & $\mathbf{0}$ & $\mathbf{1}$ & $\mathbf{2}$ & $\mathbf{3}$ & $\mathbf{4}$ & $\mathbf{5}$ & $\mathbf{6}$ & $\mathbf{7}$ & $\mathbf{8}$ & $\mathbf{9}$ & \\
\hline $\begin{array}{l}\text { No. of times digit occurs } \\
\text { in second position }\end{array}$ & 138 & 109 & 119 & 92 & 102 & 101 & 94 & 72 & 87 & 88 \\
Observed frequency (\%) & 13.772 & 10.878 & 11.876 & 9.182 & 10.180 & 10.080 & 9.381 & 7.186 & 8.683 & 8.782 \\
Expected frequency (\%) & 11.968 & 11.389 & 10.882 & 10.433 & 10.031 & 9.668 & 9.337 & 9.035 & 8.757 & 8.500 \\
Z value & 1.760 & -.509 & 1.011 & -1.296 & .157 & .441 & .048 & -2.042 & -.083 & .321 \\
P-level & .079 & .611 & .312 & .195 & .876 & .659 & .962 & .041 & .934 & .749 \\
\hline Note: Expl
\end{tabular}

Note: Expected frequencies represent Benford's probabilities for a particular digit appearing in the second digital position. $\mathrm{Z}$ values and P-levels result from a proportions test comparing the observed frequency with the expected frequency.

The higher than expected frequency of zeros as the second sales digit suggests that the sales numbers are rounded up to just across the breakpoint to increase the first digit by one. This is further evidenced by the 
significantly lower than expected rate of sevens in the second position. These findings closely resemble the results of Niskanen and Keloharju (2000) in their examination of CEM among Finnish firms. They show that Finnish companies do not limit their rounding of the second earnings digit merely from nines to zeros but round over a much wider range (i.e., all the way from sixes and sevens to zeros and ones).

The second sales digit in the current study seems to be rounded in a similar fashion. That is, the rounding occurs over a broad range with sevens rounded up all the way to zeros. With the apparent rounding of the second sales digit occurring over such a wide range, one must surmise as Niskanen and Keloharju (2000) do concerning the rounding of the second earnings digit for Finnish firms that the manipulation of sales revenue by large U.S. companies is more than merely cosmetic.

\section{CONCLUSION}

Numerous studies indicate that managers round earnings to achieve cognitive reference points in income. The current study provides strong evidence suggesting that this type of behavior also occurs with respect to the reporting of sales revenue. For the sample of large U.S. companies examined, an unusually high frequency of zeros in the second digital position of sales indicates that sales revenue is manipulated to round up the second digit to just across the breakpoint so the first digit increases by one. The lower than expected rate of sevens as the second digit for sales suggests that firms are fairly aggressive in rounding up sales. That is, the rounding margin seems quite wide since rather than rounding up the second digit from nines or even eights to zeros firms round from sevens all the way to zeros.

There could, of course, be some unknown phenomenon unrelated to management manipulation causing the data anomalies noted in the second digit of sales revenue. However, it is difficult to imagine what that factor might be considering a control procedure shows that the observed digital frequencies of the second digit in the total assets numbers for the sample firms conform almost perfectly with Benford's expected frequencies. Absent some form of manipulation, digital frequencies of the second sales digit should also follow Benford's frequencies. The fact that the observed frequencies of zeros and sevens in the second digital position for sales deviate from their expected frequencies in precisely the manner noted (i.e., more zeros and fewer sevens than anticipated) provides strong anecdotal evidence that sales revenue is manipulated to achieve cognitive reference points.

\section{SUGGESTIONS FOR FUTURE RESEARCH}

Much like the Carslaw (1988) study laid the groundwork for future research into cosmetic earnings management, the current study provides a springboard for future research into cosmetic sales management. For example, the present study considers only large publicly-traded U.S. companies. Additional research could examine firms of varying sizes to ascertain whether this manipulative behavior occurs without regard to entity size. The current study could also be replicated using companies from different countries to determine if CSM transcends national boundaries.

In addition, as Jordan et al. (2008) note, the propensity to engage in CEM appears to be related to specific company characteristics (e.g., profitability and debt leverage). Future research in CSM could determine whether certain company characteristics are associated with the likelihood that sales will be manipulated. Finally, the current study does not address how companies manipulate sales to round them up. Future research could explore the mechanisms used to achieve the rounding of sales revenue.

\section{AUTHOR INFORMATION}

Charles E. Jordan, CPA, DBA, is a professor in the School of Accountancy and Information Systems at the University of Southern Mississippi. His primary teaching and research areas are financial reporting. Dr. Jordan has on multiple occasions received the annual BellSouth Outstanding Faculty in the College of Business at the University of Southern Mississippi and was awarded the 2007-2008 Innovation in Applied Research Award for the university. He has published numerous articles in professional and academic journals, including Business Ethics 
Quarterly, Transportation Journal, Journal of Applied Business Research, Journal of Accountancy, and The CPA Journal.

Stanley J. Clark, CPA, Ph.D., is a Professor in the School of Accountancy and Information Systems at the University of Southern Mississippi. His primary teaching areas are financial and tax accounting. His research has primarily focused on financial accounting and reporting issues. He is active professionally serving as discussion leader for numerous continuing education programs for local CPAs and as a member of the AICPA Virtual Grassroots Panel. He has published articles in numerous journals, including the Journal of Business and Economic Perspectives, Academy of Accounting and Financial Studies Journal, and Oil, Gas \& Energy Quarterly.

Charlotte C. Hames is currently a senior accounting major and a Business Advisory Council Scholar at the University of Southern Mississippi. She also has a degree in Health Information Management and has several years of administrative experience in private sector hospitals. Prior to this, she served as an administrative assistant and court reporter in the U.S. Army for six years.

\section{REFERENCES}

1. Al-Attar, A. and S. Hussain, "Corporate Data and Future Cash Flows," Journal of Business Finance \& Accounting, Vol. 31, No. 7 \& 8, pp. 861-903, 2004.

2. Barth, M.E., D.P. Cram, and K.K. Nelson, "Accruals and the Prediction of Cash Flows," The Accounting Review, Vol. 76, No. 1, pp. 27-58, 2001.

3. Benford, F., "The Law of Anomalous Numbers," Proceedings of the American Philosophical Society, Vol. 78, No. 4, pp. 551-772, 1938.

4. Brenner, G.A. and R. Brenner, "Memory and Markets, or Why Are You Paying \$2.99 for A Widget," The Journal of Business, Vol. 55, No. 1, pp. 147-158, 1982.

5. Carslaw, C.A.P.N., "Anomalies in Income Numbers: Evidence of Goal Oriented Behavior," The Accounting Review, Vol. 63, No. 2, pp. 321-327, 1988.

6. Dechow, P.M. and I.D. Dichev, "The Quality of Accruals and Earnings: The Role of Accrual Estimation Errors," The Accounting Review, Vol. 77, supplement, pp. 35-59, 2002.

7. Dharan, B.G., "The Effect of Sales and Collection Disclosures on Cash Flow Forecasting and Income Smoothing," Contemporary Accounting Research, Vol. 3, No. 2, pp. 445-459, 1987.

8. Ertimur, Y., J. Livnat, and M. Martikainen, "Differential Market Reactions to Revenue and Expense Surprises," Review of Accounting Studies, Vol. 8, No. 2/3, pp. 185-211, 2003.

9. $\quad$ Francis, S., R. LaFond, P.M. Olson, and K. Schipper, "Costs of Equity and Earnings Attributes," The Accounting Review, Vol. 79, No. 4, pp. 967-1010, 2004.

10. Guan, L., H. Daoping, and D. Yang, “Auditing, Integral Approach to Quarterly Reporting, and Cosmetic Earnings Management,” Managerial Auditing Journal, Vol. 21, No. 6, pp. 569-581, 2006.

11. Hollister, J., V. Shoaf, and G. Tully, "An International Comparison of Accruals and the Prediction of Future Cash Flows," Journal of Accounting and Finance Research, Vol. 10, No. 6, pp. 1-9, 2002.

12. Johnson, P., "Fraud Detection with Benford's Law," Accountancy Ireland, Vol. 37, No. 4, pp. 16-17, 2005.

13. Jordan, C.E., S.J. Clark, and G.R. Pate, "Earnings Manipulation to Achieve Cognitive Reference Points in Income," forthcoming in Academy of Accounting and Financial Studies Journal, 2008.

14. Jordan, C.E., S.J. Clark, and M.A. Waldron, "An Analysis of the Comparative Predictive Ability of Operating Cash Flows, Earnings, and Sales," Journal of Applied Business Research, Vol. 23, No. 3, pp. 5360, 2007.

15. Kaplan, S.N., "Top Executive Rewards and Firm Performance: A Comparison of Japan and the U.S.," Journal of Political Economy, Vol. 102, No. 3, pp. 510-546, 1994.

16. Kinnunen, J. and M. Koskela, "Who Is Miss World in Cosmetic Earnings Management? A Cross National Comparison of Small Upward Rounding of Net Income Numbers Among Eighteen Countries," Journal of International Accounting Research, Vol. 2, pp. 39-68, 2003.

17. Lehman, M., M.W. Watson, and T. Jones, "Flexing Your Super Financial Sleuth Power," Journal of Accountancy, Vol. 203, No. 6, pp. 50-54, 2007.

18. Michelson, S.E., J. Jordan-Wagner, and C.W. Wootten, "A Market Based Analysis of Income Smoothing," Journal of Business Finance \& Accounting, Vol. 22, No. 8, pp. 1179-1193, 1995. 
19. Newcomb, S. "Note on the Frequency of the Use of Different Digits in Natural Numbers," American Journal of Mathematics, pp. 39-40, 1881.

20. Nigrini, M.J., “A Taxpayer Compliance Application of Benford's Laws,” The Journal of the American Taxation Association, Vol. 18, No. 1, pp. 72-91, 1996.

21. Nigrini, M.J. and L.J. Mittermaier, "The Use of Benford's Law as an Aid in Analytical Procedures," Auditing: A Journal of Practice \& Theory, Vol. 16, No. 2, pp. 52-67, 1997.

22. Niskanen, J. and M. Keloharju, "Earnings Cosmetics in a Tax Driven Accounting Environment: Evidence from Finnish Public Firms," The European Accounting Review, Vol. 9, No. 3, pp. 443-452, 2000.

23. Olsen, C. and J.R. Dietrich, "Vertical Information Transfers: The Association Between Retailers' Sales Announcements and Suppliers' Security Returns," Journal of Accounting Research, Vol. 23, No. 3, pp. 144-166, 1985.

24. Skousen, C.J., L. Guan, and W.T. Sterling, "Anomalies and Unusual Patterns in Reported Earnings: Japanese Managers Round Earnings," Journal of International Financial Management and Accounting, Vol. 15, No. 3, pp. 212-234, 2004.

25. Thomas, J.K., "Unusual Patterns in Reported Earnings," The Accounting Review, Vol. 64, No. 4, pp. 773787, 1989.

26. Van Caneghem, T., "Earnings Management Induced by Cognitive Reference Points," British Accounting Review, Vol. 34, No. 2, pp. 167-178, 2002.

27. Zheng, S.X. and D.A. Strangeland, "IPO Underpricing, Firm Quality, and Analysts Forecasts," Financial Management, Vol. 36, No. 2, pp. 45-64, 2007. 
NOTES 